\title{
Poster Colours: Pocket-Friendly Alternative to Tissue Marking Dyes
}

\section{Dear Editor,}

We read with great interest the paper "Inking in Surgical Pathology: Does the Method Matter? A Procedural Analysis of a Spectrum of Colours" published in this journal recently and wish to share our small study relating to the same topic (1).

Grossing or macroscopic examination is an integral part of evaluating any surgical specimen. Tissue inking is often employed during grossing for various indications, including identification of resection margins, to assist specimen orientation and to help identify small tissue pieces at embedding. Tissue inking is usually performed using India ink or tissue marking dyes (TMDs). India ink carries the limitation of being limited to one colour, as opposed to TMDs which come in various colours. While TMDs are excellent and are well preserved after processing, they can be rather costly, especially for small laboratories in developing countries. Studies have explored alternative marking techniques which include painting with gelatin (2), commercially available oil and acrylic paints $(3,4)$, and other routinely used dyes in histopathology laboratory such as eosin and Alcian Blue (3) as an alternative to TMDs. However, to the best of our knowledge, the use of locally available paints as alternative tissue marking techniques in Malaysia has not been explored.

We performed a study assessing the use of locally available poster colours (Buncho, Buncho Marketing Sdn Bhd, Klang, Selangor, Malaysia) in commonly used shades in tissue inking, which are black (code 31), Prussian blue (code 40) and green (code 45) and directly evaluated the colour visibility microscopically compared to tissues inked with TMDs of similar shades. Four different tissue specimens fixed in formalin were selected (breast, colon, skin and thyroid) to represent different tissue consistency and the surfaces for inking. Six tissue pieces were taken from each specimen; three were inked using TMDs and placed into one block, while the other three pieces were inked using poster colours and were placed in a separate block. The process was repeated for all of the tissue specimens. The tissues were dabbed dry with paper towels prior to, and after inking. No additional inking aids were used. The blocks were then processed using standard processing techniques. The next day, the tissues were embedded in paraffin, sectioned at $3 \mathrm{~mm}$ thickness and stained with haematoxylin and eosin (H\&E). All of the slides were examined microscopically. The colour visibility on microscopic evaluation was scored from 0 to 3 (0-No visible colour marking; 1-Faint visibility; 2-Moderate visibility and 3-Strong visibility). The results are tabulated in Table I. Examples of tissue inked with TMD and poster colour are shown in Figure 1A,B.

In general, the visibility of poster colours microscopically rivalled the TMDs, if not superior, when used without additional inking aids in the shades that we studied. All three colours used were reliable; Prussian blue appeared to be the most consistent. The type of tissue also seemed to influence colour fidelity with least visibility of the ink seen when applied on colon serosa, when no mordant was used.
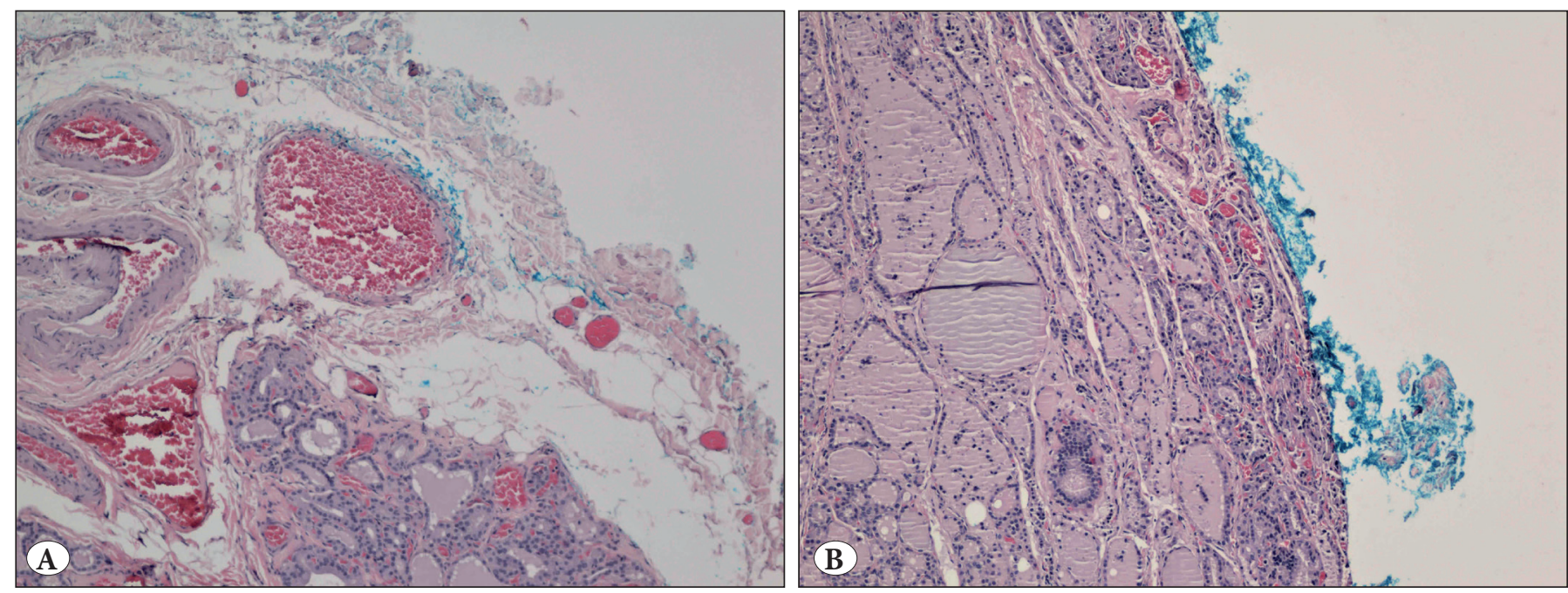

Figure 1: Thyroid specimen inked with A) TMD (H\&E; x10) and B) poster colour in the shade of Prussian blue (H\&E; x10). 
Table I: Microscopic colour visibility of different types of tissues inked with TMDs and poster colours.

\begin{tabular}{lccc}
\hline Tissue Type & Colours & TMDs & Poster Colour \\
\hline Breast & Black & 1 & 2 \\
& Blue & 2 & 3 \\
& Green & 1 & 2 \\
\hline Skin & Black & 1 & 1 \\
& Blue & 1 & 3 \\
& Green & 1 & 3 \\
\hline Colon serosa & Black & 1 & 1 \\
& Blue & 1 & 1 \\
& Green & 0 & 1 \\
\hline Thyroid capsule & Black & 1 & 2 \\
& Blue & 1 & 3 \\
& Green & 0 & 2 \\
\hline
\end{tabular}

Scores: 0 -No visible colour marking; 1-Faint visibility; 2-Moderate visibility and 3-Strong visibility.

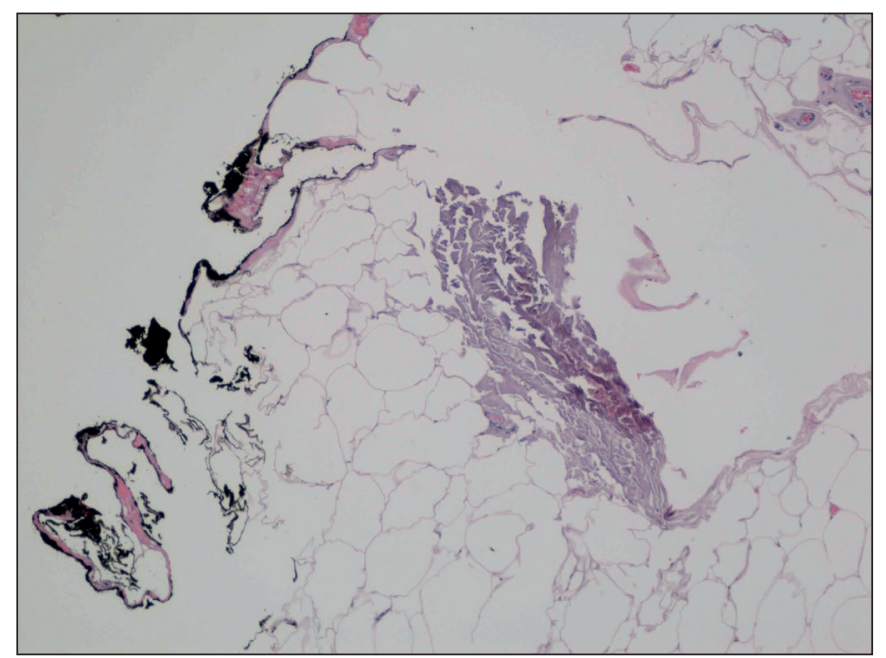

Figure 2: Routine breast specimen inked using poster colour in the shade of black (H\&E; x10).
There was minimal seepage of colour into underlying tissue substance. There was no difference in the quality of the tissue sections or staining compared to other non-inked tissues processed on the same day.

Poster colour is a form of acrylic paint, which is widely used for painting and artwork. As previously demonstrated, acrylic paints do appear to be a reliable, cheaper substitute for tissue marking hence providing an excellent option for financially-constrained small laboratories (3-5). Furthermore, its vast array of available shades of colours confers an advantage over India ink, gelatin, and even TMDs. It needs to be borne in mind however that these alternative paints should be tested in individual laboratories prior to routine use to ensure reproducibility of the results when using locally available acrylic / poster paints. We have since successfully used poster colours in select shades to ink routine surgical specimens in our laboratory (Figure 2).

\section{REFERENCES}

1. Pursnani D, Arora S, Katyayani P, C A, Yelikar BR. Inking in surgical pathology: Does the method matter? A procedural analysis of a spectrum of colours. Turk Patoloji Derg. 2016;32:1128.

2. Shinde V, Phelan C, Gater W, Thomas J. Inking a specimen without the mess. J Clin Pathol. 2008;61:783.

3. Tampi C. In Search of the Rainbow: Colored inks in surgical pathology. Indian J of Pathol and Microb. 2012;55:154-7.

4. Chiam HW, Phillip GM, Hoffman GJ. Marking the surgical margins of specimens: Commercial acrylic pigments are reliable, rapid and safe. Pathology. 2003;35:204-6.

5. Salerno A, Trent P, Jackson PJ, Cook MG. A rapid and safe method to fix India ink on specimen resection margins. J Clin Pathol. 1995;48:689-90.

\section{Mardiana ABDUL AZIZ}

Anatomic Pathology Unit, Centre for Pathology Diagnostic and Research Laboratories (CPDRL), Faculty of Medicine, Universiti Teknologi MARA, SG BULOH, SELANGOR, MALAYSIA

E-mail: mars_aziz@yahoo.com

Phone: +6 (03) 61267435

Nor Salmah BAKAR

Anatomic Pathology Unit, Centre for Pathology Diagnostic and Research Laboratories (CPDRL), Faculty of Medicine, Universiti Teknologi MARA, SG BULOH, SELANGOR, MALAYSIA

\section{Noor Kaslina MOHD KORNAIN}

Anatomic Pathology Unit, Centre for Pathology Diagnostic and Research Laboratories (CPDRL), Faculty of Medicine, Universiti Teknologi MARA, SG BULOH, SELANGOR, MALAYSIA 